\title{
CONCEPÇÕES DA PROFESSORA ACERCA DO ABUSO SEXUAL INFANTIL
}

\author{
RACHEL DE FARIA BRINO \\ quelbrino@bol.com.br \\ LÚCIA CAVALCANTI DE ALBUQUERQUE WILLIAMS \\ williams@power.ufscar.br \\ Laboratório de Análise e Prevenção da Violência da Universidade \\ Federal de São Carlos-SP
}

\begin{abstract}
RESUMO
A escola mostra-se como lugar ideal para detecção e intervenção em casos de abuso sexual infantil, uma vez que o principal agressor geralmente encontra-se na família. Considerando que a escola deve ter como objetivo garantir a qualidade de vida de sua clientela, bem como promover a cidadania, para delinear um programa que possa capacitar tais profissionais em casos de abuso sexual, parece necessário, em primeiro lugar, conhecer o universo de informações que eles detêm sobre o tema, sobre a legislação a respeito e sobre os direitos da criança. Este estudo teve como objetivo caracterizar as informações de 20 educadoras de escolas municipais de educação infantil sobre o abuso sexual de crianças em uma cidade de médio porte. As informações obtidas foram analisadas e divididas em sete categorias. Os resultados indicam que a maioria das educadoras possuía informações insuficientes acerca do tema e afirmava adotar procedimentos inadequados diante dos casos de crianças que sofreram abusos sexuais.

CRIANÇA-ABUSOSEXUAL - EDUCAÇÃODACRIANÇA-PROFESSOR
\end{abstract}

\section{ABSTRACT}

TEACHERS' CONCEPTIONSABOUTSEXUAL CHILDABUSE. The schoo/proves to be an ideal place for detection and intervention in child sexual abuse cases, since the main aggressor is found generally within the family. Considering that one of the school's objectives should be to guarantee the quality of life of its pupils, as well as to promote citizenship, in order to develop a program to train teachers on what to do in cases of sexual abuse, it seems necessary first to survey the universe of information teachers have about the subject, the existing legislation, and the children's rights. This study aimed to characterize the information that twenty educators in municipal schools for early child education in a medium size city had about child sexual abuse. The data

Este artigo é parte da dissertação de mestrado da primeira autora, desenvolvida pelo Programa de Pós-Graduação em Educação Especial da Universidade Federal de São Carlos - UFSCar - e financiada pela Fundação de Amparo à Pesquisa - Fapesp. 
obtained were analyzed and divided into seven categories. The results indicate that the majority of educators had insufficient information on the subject, affirming as well that they took inadequate measures when faced with cases of children who suffered sexual abuse.

CHILDREN-SEXUALABUSE-UPBRINGING - TEACHER

O abuso sexual pode ser definido, como "qualquer interação, contato ou envolvimento da criança em atividades sexuais que ela não compreende, não consente, violando assim as regras sociais e legais da sociedade" (Pires, 1999). A escoIha do abuso sexual como enfoque do trabalho considera o fato de este ser, dentre os abusos, aquele que provoca os piores prejuízos psicológicos para a vítima (Caminha, 1999; Monteiro, Abreu, Phebo, 1997; Azevedo, Guerra, 1997). Esses prejuízos podem ser dificuldades de adaptação interpessoal, sexual e afetiva (Azevedo, Guerra, 1997). O abuso sexual é considerado uma "modalidade privilegiada" de violência doméstica contra a criança, na medida em que além das práticas sexuais propriamente ditas pode implicar agressão física e abuso emocional (Azevedo, Guerra, Vaiciunas, 1997).

Os dados epidemiológicos sobre o abuso sexual na literatura brasileira não são abrangentes, correspondendo a locais isolados e amostras parciais. Além disso, os dados levantados em delegacias, conselhos tutelares e ambulatórios não refletem a realidade das ocorrências. Estudos do Instituto Médico Legal - IML - e do Programa de Atenção a Vítimas de Abuso Sexual - Pavas - em São Paulo, avaliam que apenas 10\% a 15\% dos casos são revelados. A omissão deve-se ao fato de esse tipo de violência ser acompanhado de culpa e vergonha, sendo que na maioria das vezes, como ocorre dentro de casa, tal violência permanece, no dizer de Saffioti (1996), "silenciosa". A autora estudou vítimas de abuso sexual as quais revelaram que tal abuso é o segredo mais bem guardado. A verdadeira incidência dos crimes sexuais é desconhecida, devendo ser um dos delitos de maior subnotificação e sub-registro. Outro indício que corrobora as afirmações acima é que o agressor, nos casos de abuso sexual intrafamiliar, em 69,6\% dos casos é o pai, em 29,8\% é o padrasto e em 0,6\% é o pai adotivo (Saffioti, 1996). O estudo, em que Drezett (2000) analisou I.200 casos de violência sexual documentados no Hospital Pérola Byington de São Paulo, constata por sua vez que em $84,5 \%$ dos casos de violência sexual contra a criança o agressor era conhecido da vítima, sendo que em 21 ,7\% o pai era o agressor, em 16,7\% o padrasto, em I,6\% o pai adotivo, em I I,6\% era o tio, em $10 \%$ o avô, em 16,7\% o vizinho e em 21 , $7 \%$ o agressor era outro conhecido da família. 
A incidência de abuso sexual no círculo familiar é bastante superior aos casos de abuso extrafamiliar, sendo que este último ocorre em apenas $15 \%$ dos casos notificados (Flores, 1998). Uma vez que o principal agressor sexual encontra-se na família, a escola mostra-se como local ideal para detecção e intervenção junto a tais casos.

A violência por abuso sexual é mais difícil de ser identificada por não apresentar, na maioria dos casos, marcas físicas. Se aos profissionais envolvidos com a criança fosse possibilitado acesso à capacitação continuada, a identificação de vítimas possivelmente tornar-se-ia mais fácil. Não há contudo relatos na literatura brasileira que procurem levantar um perfil do professor no que se refere a suas concepções acerca do abuso sexual. Considerando que a escola deve ter como objetivo garantir a qualidade de vida de sua clientela, bem como promover a cidadania, urge capacitar professores para enfrentarem a difícil questão do abuso sexual infantil. Entretanto, para delinear um programa que possa capacitar tais profissionais, parece ser necessário conhecer primeiramente qual o universo de informação que os professores detém acerca dos conhecimentos básicos sobre o abuso sexual, a legislação que envolve o tema e os direitos da criança.

A escolha de professores de pré-escola para este estudo leva em conta a demora na revelação da ocorrência do abuso. A média de idade das crianças abusadas sexualmente aparece mais elevada nas pesquisas, sendo que do primeiro contato sexual até a revelação pode decorrer muito tempo, sugerindo que o primeiro contato pode ter ocorrido em uma faixa etária bem mais jovem (Cunningham, Sas, 1995). Além disso, crianças menores (com até seis anos de idade) apresentam maior dificuldade de relatar o abuso, pois não têm condições cognitivas e verbais necessárias para articular a violência e proporcionar recordações dos eventos (Vogeltanz, Drabman, 1995). Assim sendo, educadores treinados poderiam identificar, mais precocemente, sintomas do abuso nessa faixa etária e promover uma intervenção mais cedo, com o intuito de evitar ou amenizar as conseqüências imediatas do abuso sexual (Fagot et al., 1989).

Em um estudo que envolvia conhecimento e atitudes de diferentes grupos de profissionais em relação ao abuso de crianças, Hazzard e Rupp ( 1986) verificaram que profissionais de saúde mental e pediatras eram mais bem informados que professores. Resta levantar e conhecer o repertório de informações sobre abuso sexual desses professores para que se possam promover novas investigações sobre como envolver professores em cursos de capacitação acerca do tema. 


\section{OBJETIVO}

Caracterizar o universo de informações de professores de escolas municipais e educação infantil - Emeis - de uma cidade de porte médio do Estado de São Paulo, acerca: a) do Estatuto da Criança e do Adolescente - ECA -, no que diz respeito à violência doméstica contra crianças; b) dos sintomas apresentados por uma criança sexualmente abusada e c) dos procedimentos e ações adotados perante um caso de abuso sexual.

\section{MÉTODO}

Participantes. Previu-se inicialmente que 48 professoras participariam do estudo (sendo duas de cada Emei do município). Depois de feito o convite, apenas 20 professoras aceitaram participar. Com relação à idade das participantes, houve uma variação de 3 I a 6 I anos, sendo que 12 concentraram-se na faixa etária de 30 a 39 anos. A maior freqüência encontrada, quatro, tinham entre 40 a 49 anos, três, entre 50 a 59 anos, e uma estava na faixa etária de 60 a 69 anos.

No que diz respeito à experiência profissional com classes de Emeis, houve uma variação de três a 30 anos, sendo que nove dentre as 20 participantes concentraram-se na faixa de um a nove anos de experiência, dez na faixa de dez a 19 anos, e uma na faixa de 30 a 39 anos.

Em relação à formação profissional, o curso mais citado foi o de magistério, sendo que 19 disseram tê-lo cursado e dentre estas, seis mencionaram-no como único curso de formação. O colegial foi freqüentado por cinco participantes, o curso de pedagogia por oito participantes (sendo que duas ainda o estão cursando), biblioteconomia, letras e geografia foram cursados por uma participante cada um, enquanto os cursos de história e de educação física foram cursados respectivamente por duas participantes. Apenas 16 participantes fizeram algum curso de atualização e especialização após a formação. $\bigcirc$ curso de atualização mais freqüentado foi o de reciclagem oferecido pela prefeitura. Apenas uma professora freqüentou um curso sobre educação sexual, embora quando questionada, disse que este não havia tratado do tema abuso sexual infantil.

Instrumento de coleta de dados. Utilizou-se um roteiro semi-estruturado para entrevista das professoras, com os seguintes tópicos: I . dados pessoais (idade, tempo de profissão); 2. formação (grau de escolaridade, instituição, cursos de atualização); 3. informações sobre o ECA (conhecimentos gerais e, mais especificamente no que diz respeito à violência doméstica contra crianças e adolescentes); 4. conhecimentos sobre abuso sexual (sintomas que uma criança apresenta quando sofre abuso 
sexual, principalmente relacionados à sala de aula; atitudes a serem tomadas diante de um caso dessa natureza e apoio a essas crianças). O roteiro foi construído com base em artigo referente à violência doméstica (Williams, 200 I).

Procedimento. Antes da realização das entrevistas, foram simuladas algumas entrevistas para teste do instrumento com educadoras de uma escola particular que trabalhavam com crianças maiores (faixa etária de 7 a 14 anos). Tal simulação permitiu reformulações identificadas como necessárias e cálculo do tempo médio de duração.

Fez-se um pedido de autorização à prefeitura e às diretoras das escolas municipais, por meio de uma carta de solicitação para ingressar na escola e realizar as entrevistas. Na carta havia informações acerca do estudo, seus objetivos, entrevista, orientador responsável e telefone para contato. Foi realizado em seguida, um agendamento das entrevistas com cada educadora, proporcionando a ela informações sobre o estudo. Esse contato prévio com a educadora permitiu que a participante pudesse sentir-se mais a vontade para falar sobre o tema, que trata de uma questão um tanto "delicada" e pouco abordada. As entrevistas foram realizadas individualmente e no local em que a educadora lecionava. No início houve uma conversa, visando a criar um "clima" agradável para as entrevistas, que foram gravadas com autorização prévia e por escrito das educadoras entrevistadas, excetuando-se duas professoras que não autorizaram. As informações foram posteriormente transcritas. Durante as entrevistas em que não foi permitido gravar, foram feitos registros breves e, posteriormente, registros mais completos.

\section{RESULTADOS E DISCUSSÃO}

As informações obtidas por meio das entrevistas com as professoras foram agrupadas em sete categorias para análise: I. informações sobre o ECA em geral; 2. informações sobre o ECA no que diz respeito a abuso sexual (genéricas e específicas); 3. informações sobre abuso sexual referentes à outra fonte; 4. informações de casos de abuso sexual; 5. procedimentos e ações adotadas em relação a um caso; 6. sintomas da criança sexualmente abusada e 7. crenças das educadoras.

\section{Informações gerais a respeito do ECA}

A maioria das professoras afirmou ter lido o ECA (80\%), e no entanto notase que mais da metade dessas educadoras (56,3\%) afirmou ter lido brevemente ou apenas algumas partes. Tais dados sugerem que grande parte delas não dispõe de informações suficientes sobre o Estatuto da Criança e do Adolescente. 


\section{Informações sobre o ECA em relação a abuso sexual}

a. Questóes genéricas

Apenas 15\% das participantes foram capazes de enunciar alguma informação sobre abuso sexual contida no Estatuto, sugerindo que a grande maioria não havia assimilado ou não era capaz de verbalizar informações acerca do abuso sexual que nele estivessem contidas.

Três professoras informaram algo referente a abuso sexual encontrado no documento. Uma delas apresentou a seguinte informação: "A criança é afastada da família quando é identificado o abuso sexual". Tal afirmação, porém, não é encontrada no ECA da maneira como foi expressa pela educadora. $\bigcirc$ art. 130 do Estatuto tem a seguinte redação: "Verificada a hipótese de maus-tratos, opressão ou abuso sexual impostos pelos pais ou pelo responsável, a autoridade judiciária poderá determinar, como medida cautelar, o afastamento do agressor da moradia comum" (São Paulo, 1997, p.38). Portanto, a medida relativa a afastar a criança do agressor consistiria em que este seja retirado do lar e não a criança.

Outra professora apresentou a seguinte informação: "Quando houver gravidez decorrente de abuso sexual, o aborto é permitido", mas tal afirmação não é encontrada em qualquer um dos artigos do Estatuto; é porém condizente com o Código Penal Brasileiro.

A terceira participante que apresentou informação escreveu: "Se a professora ou diretora tomar conhecimento de um caso de abuso sexual deve comunicar o Conselho Tutelar". Tal afirmação é condizente, correspondendo ao art. 245 do Estatuto da Criança e do Adolescente:

Deixar o médico, professor ou responsável por estabelecimento de atenção à saúde e de ensino fundamental, pré-escola ou creche, de comunicar à autoridade competente os casos de que tenha conhecimento, envolvendo suspeita ou confirmação de maus-tratos contra criança ou adolescente:

Pena: - multa de 3 a 20 salários de referência, aplicando-se o dobro em caso de reincidência. (São Paulo, 1997, p.55)

Parece ser possível concluir que a maioria das professoras não domina informações sobre o conteúdo do Estatuto acerca do abuso sexual, e que aquelas capazes de fornecer alguma informação, exceto uma, não o fizeram de forma correta e condizente com o Estatuto. 


\section{b. Questões específicas}

Quando a pergunta foi específica sobre o dever do profissional acerca de o que fazer em casos de abuso sexual, segundo o Estatuto, mais da metade das professoras (60\%) apresentou informações, sugerindo que elas conheciam algo sobre o Estatuto, o que difere dos dados anteriores relativos à pergunta aberta.

Dentre as informações apresentadas sobre o dever do profissional em caso de identificação de abuso sexual, todas as respostas dadas envolviam denúncia, variando na forma de proceder (ver Tabelal).

\section{TABELA I}

INFORMAÇÕES SOBRE O DEVER DO PROFISSIONAL EM CASOS DE ABUSO SEXUAL

\begin{tabular}{l|c|c}
\hline Informações apresentadas & Freqüência & Porcentagem \\
\hline Denunciar & 9 & $75 \%$ \\
Denunciar e encaminhar pais ao Conselho Tutelar & 1 & $8,3 \%$ \\
Procurar ajuda especializada para proceder à denúncia & 1 & $8,3 \%$ \\
Falar com a família e se esta não tomar atitude & & \\
encaminhar ao Conselho Tutelar & 1 & $8,3 \%$ \\
\hline Total & 12 & $100 \%$ \\
\hline
\end{tabular}

\section{Informações sobre abuso sexual referente à outra fonte}

Como outra fonte de informações que não o Estatuto, os meios de comunicação apareceram predominantemente (ver Tabela 2).

TABELA 2

OUTRAS FONTES DE INFORMAÇÃO SOBRE ABUSO SEXUAL

\begin{tabular}{l|c|c}
\hline Outras fontes de informação & Freqüência & Porcentagem \\
\hline Meios de Comunicação & 23 & $69,7 \%$ \\
Escola (comentários) & 7 & $21,2 \%$ \\
Favela & 1 & $3,3 \%$ \\
Curso no Conselho Tutelar & $\mathrm{I}$ & $3,3 \%$ \\
Outros locais & $\mathrm{I}$ & $3,3 \%$ \\
\hline Total & 33 & $100 \%$ \\
\hline
\end{tabular}


Referindo-se mais especificamente à televisão, houve um programa de auditório citado por duas professoras em particular: Programa do Ratinho(ver Tabela 3), veiculado pela emissora Sistema Brasileiro de Televisão - SBT. Esse programa já feriu, no passado, os direitos da criança, com exemplos de sensacionalismo popularesco, haja vista a exposição de um vídeo de espancamento e tortura de uma criança. Dessa forma, fontes de informação como programas de auditório, além de não informarem adequadamente sobre o assunto, podem contribuir para perpetuar as crenças inadequadas e estereótipos sobre o assunto. Não apareceram como fontes de informação sobre o tema, livros e artigos, que provavelmente possuem um caráter mais informativo e científico que os meios televisivos, principalmente em se tratando de programas da natureza do mencionado.

TABELA 3

MEIOS DE COMUNICAÇÃO COMO FONTE DE INFORMAÇÃO

\begin{tabular}{l|c|c}
\hline Meios de Comunicação & Freqüência & Porcentagem \\
\hline Televisão & 12 & $52,2 \%$ \\
Jornal & 05 & $21,7 \%$ \\
Revista & 02 & $8,7 \%$ \\
Rádio & 02 & $8,7 \%$ \\
Cinema & 01 & $4,3 \%$ \\
Mídia em geral & 01 & $4,3 \%$ \\
\hline Total & 23 & $100 \%$ \\
\hline
\end{tabular}

Apenas uma participante citou um curso oferecido pelo Conselho Tutelar, demonstrando a escassez de cursos de capacitação sobre o tema.

\section{Informações de casos de abuso sexual}

A maioria das participantes (65\%) disse já ter tido informações sobre casos de abuso sexual, sendo que $26,7 \%$ não quiseram especificar a procedência da vítima, ou seja, informar se o caso relatado envolvia criança de sua própria classe, de sua própria família, de vizinhos, de parentes etc., demonstrando, talvez, receio de fornecer essa informação. É possível que o receio esteja relacionado à ocorrência de abuso sexual dentro de sua própria casa, de algum parente ou amigo próximo, ou mesmo dentro da própria escola ou classe, e que a professora tenha tido medo de represálias ou de expor-se. 
Das participantes que souberam de casos, 20\% relataram ter tido conhecimento de um fato envolvendo uma criança de sua própria classe (ver Tabela 4), portanto, um número expressivo de participantes já teve de lidar diretamente com casos de abuso sexual na escola, reforçando a necessidade de informação sobre procedimentos adequados em casos de abuso sexual.

TABELA 4

PROCEDÊNCIA DA VÍTIMA DE ABUSO SEXUAL SEGUNDO INFORMAÇÕES DAS PESQUISADAS

\begin{tabular}{l|c|c}
\hline Procedência da vítima & Freqüência & Porcentagem \\
\hline Local não especificado & 4 & $26,7 \%$ \\
Própria escola, fora de sua classe & 3 & $20 \%$ \\
Bairro da própria escola & 3 & $20 \%$ \\
Sua própria classe & 3 & $20 \%$ \\
Outra escola & 1 & $6,6 \%$ \\
Favela & 1 & $6,6 \%$ \\
\hline Total & 15 & $100 \%$ \\
\hline
\end{tabular}

\section{Procedimentos e ações diante de um caso}

No que se refere a procedimentos e ações perante um caso de abuso sexual, 95\% das participantes disseram que tomariam algum tipo de atitude, o que parece ser um dado bastante encorajador. Cabe aqui ressaltar que muitas vezes há uma diferença expressiva entre o que se afirma sobre algo e o que realmente se faz. Não é possível isolar o relato verbal da participante do estudo, sendo que a resposta pode receber influência de vários fatores (Perone, 1988).

Dentre as que afirmaram que fariam algo perante um caso de abuso sexual, apenas quatro (21\% do total, $n=19$ ) tomariam atitudes que envolveriam a denúncia do caso, demonstrando que apenas uma pequena porcentagem da amostra faria o que o Estatuto da Criança e do Adolescente estabelece. As outras 15 professoras (79\% do total, $n=19)$ tomariam outra atitude que não a denúncia.

Seis participantes citaram atitudes consideradas inadequadas, tais como chamar os pais para uma conversa (21,05\% do total) e tentar ajudar a criança em sala sem comunicar o ocorrido a terceiros ( $10,50 \%$ do total), o que demonstra um 
certo despreparo e falta de informação a respeito do que um professor deve fazer ao identificar um caso de abuso sexual, podendo até, em certos casos, prejudicar a criança vitimada e/ou colocar a sua própria segurança em risco (ver Tabela 5). Como exemplo de conseqüências que ações inadequadas podem gerar, cabe mencionar o perigo de exposição a pais que podem ser violentos e ameaçadores, que podem infligir danos tanto ao professor como à criança. Além disso, a recusa de procurar auxílio ou ajuda especializada e a tentativa de ajudar a criança, conversando com ela, faz com que o problema do abuso se perpetue, expondo a criança a um risco extremo.

Finalmente, se a própria criança revelou o abuso ao professor e este nada fez, a omissão passará à criança a mensagem de que o abuso pode não ter sido grave ou que o professor acredite que a criança esteja mentindo.

TABELA 5

PROCEDIMENTOS QUE ADOTARIA DIANTE DE UM CASO DE ABUSO SEXUAL

\begin{tabular}{l|c|c}
\hline Procedimentos & Freqüência & Porcentagem \\
\hline Procurar a direção da escola & 9 & $47,4 \%$ \\
Denunciar o caso & 3 & $15,8 \%$ \\
Procurar os pais & 3 & $15,8 \%$ \\
Conversar e ajudar a criança em sala & 2 & $10,5 \%$ \\
Conversar com os responsáveis, falar com um & & $5,3 \%$ \\
especialista e procurar a Delegacia de Defesa da Mulher & 1 & $5,3 \%$ \\
Conversar com a diretora e chamar os pais & 1 & $100 \%$ \\
\hline Total & 19 & \\
\hline
\end{tabular}

\section{Sintomas da criança sexualmente abusada}

Dentre os sintomas citados pelas professoras (ver Tab. 6), grande parte é descrita pela literatura sobre o tema (Meichenbaum, 1994; Monteiro, Abreu, Phebo, 1997; Caminha, 1999; Pires, 1999; Azevedo, Guerra, 1997, Williams, 200 Ia). As exceções foram: a. carência e irritação, que talvez por serem termos vagos não foram descritos em estudos como sintomas de abuso sexual e, b. falar sobre o problema - ao contrário, a literatura aponta que a criança que sofreu ou está sofrendo abuso sexual demonstra dificuldades em relatar o fato. 
Dentre os sintomas listados, alguns freqüentemente citados na literatura da área não apareceram nas verbalizações das educadoras, tais como problemas no sono (pesadelos, viǵlia), fugir de casa ou evitar voltar para casa após a escola, evitar o toque de outras pessoas, desenvolvimento de fobias etc. De qualquer maneira, apenas citar alguns sintomas parece não ser suficiente para identificar ocorrência de abuso sexual. É necessário um treinamento aprofundado para que a professora saiba identificar um conjunto de sintomas, além de avaliar o contexto da criança, como: quando começaram a ocorrer tais sintomas, se foi um processo, se foi de repente, se esses sintomas têm permanecido por um período longo.

É interessante notar, ainda, que o comportamento mais freqüentemente apontado pela literatura como sintomático de abuso sexual - comportamentos sexualizados - foi mencionado apenas por uma participante, reforçando a hipótese de que as professoras detêm um conhecimento superficial acerca do tema.

TABELA 6

SINTOMAS APRESENTADOS PELA CRIANÇA SEXUALMENTE ABUSADA

\begin{tabular}{l|c|c}
\hline Comportamentos & Freqüência & Porcentagem \\
\hline Retraída, isolada e quieta & 12 & $26,1 \%$ \\
Agressiva & 12 & $26,1 \%$ \\
Medrosa & 7 & $15,3 \%$ \\
Fala sobre o problema & 3 & $6,5 \%$ \\
Envergonhada & 2 & $4,4 \%$ \\
Triste & 2 & $4,4 \%$ \\
Carente & 1 & $2,2 \%$ \\
Desconfiada & 1 & $2,2 \%$ \\
Irritada & 1 & $2,2 \%$ \\
Passiva & 1 & $2,2 \%$ \\
Comportamentos regressivos & 1 & $2,2 \%$ \\
Comportamentos sexualizados & 1 & $2,2 \%$ \\
Problemas de aprendizagem & 1 & $2,2 \%$ \\
\hline Total & 45 & $100 \%$ \\
\hline
\end{tabular}

De modo geral, entretanto, parece ser possível concluir, com base na tabela 6 , que a maioria das educadoras é capaz de informar sobre algum comportamento que uma criança sexualmente abusada apresenta. 


\section{Crenças das professoras}

Das participantes, I 3 (65\%) apresentaram crenças ou verbalizações inadequadas em relação ao tema.

As "crenças" inadequadas foram agrupadas segundo sua natureza e classificadas nas seguintes categorias:

a. utilização de procedimentos inadequados (isto é, que ferem a legislação) em relação a um possível caso de abuso sexual infantil, como:

Olha, em primeiro lugar eu acho que eu iria falar com os pais, eu procuraria os pais e iria tentar descobrir o que está acontecendo em casa.

...eu falaria com a mãe e se ela entendesse, ajudasse, procuraria encaminhar a mãe e a criança.

...em primeiro lugar eu procuraria conversar realmente com os responsáveis pela criança, para saber o que realmente está acontecendo, o que levou a pessoa a fazer aquilo, certo.

....lha, muitas vezes aconteceu exatamente com parentes próximos, então, às vezes, não tem como a gente ter contato, nem falar diretamente com a família, a gente tem que orientar a criança a não se envolver, porque é uma situação delicada, a gente não sabe proceder, porque você sente que está invadindo.

...depois chamaria os pais da criança.

...no meu caso, como eu só lidava com a criança ali, não era como a assistente social que tinha contato externo com a família, visitava, como era só ali dentro eu fazia pouco, só podia conversar com a criança.

b. concepção errônea de que o abuso sexual infantil está associado apenas a baixo poder aquisitivo ou visão estereotipada sobre o nível socioeconômico da vítima:

...é claro que se uma família mora todo mundo junto no mesmo cômodo facilita, influencia bastante.

...e eu chegando lá eram crianças da favela, então a coisa ali é gritante,..., criança de seis anos que foi abusada.

...olha de criança de Emei não, é uma escola onde as crianças vêem de uma classe social um pouquinho melhor ... mas geralmente acontece na inferior, com mais incidência que na outra classe, então aqui a gente nunca teve problema de nada. ...aqui não tem essas coisas viu, eu acho.

c. concepçôes errôneas sobre sintomas comportamentais que as crianças sexualmente abusadas apresentam: 
A criança fala, ela conta quando ocorreu algo diferente..., a criança pequena ela geralmente fala, ela conta.

...eu acho importante ressaltar que os comportamentos apresentados pela criança são conforme a faixa etária.

...se ela assim pinta muito bonitinho eu acho que ela começa deixar de lado essa pintura e começa a pintar mais com cores negras.

d. visões estereotipadas de gênero que podem, inclusive, culpar a vítima:

Mudou, ela ficou, eu não sei se ela gostou, porque ela ficou mais atirada, sabe, com roupas decotadas.

E ela é bonitinha, ela tem corpinho de moça, já.

e. conhecimento inadequado da função e legitimidade do ECA:

Nunca peguei para estudar, nunca precisei, nunca tive problema grave.

f. concepção errônea de que o abuso sexual só ocorre em determinadas faixas etárias:

Mas aqui na classe não, os meus alunos são bem novinhos, têm quatro anos, eu trabalho com uma faixa etária ainda bem respeitada.

g. visão de senso comum acerca do agressor sexual:

...é uma pessoa desumana fazendo isso, então ela não merece nenhum tipo de compaixão, de dó, que eu vá ter dó dela.

\section{CONCLUSÕES}

Por meio da análise das categorias utilizadas na descrição dos resultados, podem ser destacados diversos aspectos referentes ao universo de informações das educadoras, concernentes à questão do abuso sexual infantil.

A formulação da pergunta a respeito do ECA, interferiu na resposta obtida. A pergunta mais específica parece ter permitido respostas mais claras e diretas, enquanto a pergunta mais geral suscitou respostas vagas e imprecisas.

No que se refere às outras fontes de informação, que não o ECA, pode-se perceber a falta de acesso das professoras a fontes mais adequadas, como livros, artigos, cursos. A lacuna na formação das professoras não permite ou dificulta que detenham informações apropriadas sobre abuso sexual e sobre os meios corretos de se lidar com esse grave problema. 
A não disponibilização de informações referentes à procedência da vítima reforça o "tabu" que ainda cerca a questão do abuso sexual; além disso, o número significativo de professoras que já tiveram de lidar com vítimas entre as crianças de sua classe chama a atenção para a farta existência do fenômeno a despeito deste ainda ser um tabu.

Um outro aspecto a ser destacado refere-se às afirmações das educadoras sobre procedimentos que adotariam diante dos casos de abuso sexual infantil. Ao afirmar que fariam algo nesses casos, é possível que as educadoras tenham pretendido dar respostas socialmente aceitáveis. Em contraste, merecedor de maior ênfase, destaca-se o baixo número de participantes que faria uma denúncia, tal como exige a legislação. O não envolvimento de denúncia nas respostas das demais participantes pode estar relacionado a três hipóteses: a. desconhecimento do ECA, que não só coloca a denúncia como obrigatória, como também prevê pena ao professor que se omite da denúncia; b. medo de represálias dos pais ou responsáveis pela criança; c. crenças inadequadas sobre o papel do professor, relativas ao envolvimento em problemas familiares dos alunos.

No último aspecto a ser ressaltado, o que as participantes informaram sobre o dever do professor e o que efetivamente fariam ao se deparar com um caso de abuso sexual em sua classe, nota-se um descompasso. As educadoras foram capazes de informar qual era o seu dever, segundo o Estatuto, diante de casos de abuso sexual (60\% informaram que seu dever consistia em denunciar o caso), e, no entanto, quando questionadas sobre o que fariam efetivamente ao se deparar com um caso em sua classe, apenas $20 \%$ afirmaram que o denunciariam.

A correspondência entre o "dizer" e o "fazer" já foi amplamente discutida. Perone ( 1988) aponta que não é possível isolar o relato verbal do participante do estudo, uma vez que a fala da educadora pode estar sendo influenciada por vários fatores, como, por exemplo, aceitação social, podendo, portanto, não corresponder ao que ela realmente faria diante de um caso de abuso sexual. Outra ressalva do autor refere-se ao fato de que a relação entre a descrição verbal e a execução da ação pode ser vista essencialmente como correlacional e não causal, isto é, afirmar que alguém tomaria alguma atitude não necessariamente torna a ação mais provável.

Há necessidade, portanto, de estudos mais aprofundados, envolvendo a utilização da legislação como o ECA, por parte dos profissionais que trabalham diretamente com crianças. Adicionalmente a tais estudo, há necessidade de se verificar e avaliar quais os meios adequados para que educadores que trabalham com crianças adotem os procedimentos necessários nos casos de abuso sexual de forma efetiva para que um maior número de denúncias seja feito. 
Cabe ressaltar a importância de tecer alguns comentários finais sobre o pequeno número de participantes do estudo. A sua baixa adesão $(41,6 \%)$ pode estar relacionada ao desconforto que o tema abuso sexual infantil ainda acarreta nas pessoas. Futuros estudos poderão ampliar a amostra e atestar sobre a generalidade dos resultados. Este trabalho, contudo, serviu como ponto de partida para um programa de capacitação de professores para lidar com abuso sexual infantil.

\section{REFERÊNCIAS BIBLIOGRÁFICAS}

AZEVEDO, M. A.; GUERRA, V. N. A. As Políticas sociais e a violência doméstica contra crianças e adolescente: um desafio recusado em São Paulo? In: AZEVEDO, M. A.; GUERRA, V. N. A. Infância e violência doméstica: fronteiras do conhecimento. São Paulo: Cortez, 1997. p. 227-256.

AZEVEDO, M. A.; GUERRA, V. N. A.; VAICIUNAS, N. O Incesto ordinário: a vitimização sexual doméstica da mulher-criança e suas consequêencias psicológicas. In: AZEVEDO, M. A.; GUERRA, V. N. A. Infância e violência doméstica: fronteiras do conhecimento. São Paulo: Cortez, 1997. p.195-209.

BRINO, R. F. Capacitação do educador acerca do abuso sexual infantil. 2002. Dissertação (Mestrado) Programa de Pós-Graduação em Educação Especial, UFSCar, São Carlos.

CAMINHA, R. M. A. Violência e seus danos à criança e ao adolescente. In: AMENCAR (org.). Violência doméstica. Brasília: Unicef, 1999. p.43-60.

CUNNINGHAM, A. H.; SAS, L. D. Tipping the balance to tel/ secret. the public discovery of child sexual abuse. Ontario: London Family Court Clinic, 1995. The Role of school programs in disclosure.

DREZETT, J. Aspectos biopsicossociais da violência sexual. Jornal da Rede Pública, n. 22, p.|8-21, 2000.

FAGOT, B. I. et al. Comparison of the play behaviors of sexually abused, physically abused, and nonabused preschool children. Topics in early childhood special education, v. 9, n. 2, p.88-100, 1989.

FLORES, R. Z. Definir e medir o que são abusos sexuais. In: LEAL, M. F. P.; CÉSAR, M. A. (orgs.). Indicadores de violência intrafamiliar e exploração sexual comercial de crianças e adolescente. Brasilia: Ministério da Justiça, 1998.

HAZZARD, A.; RUPP, G. A Note on the knowledge and attitudes of professional groups towards child abuse. Journal of Community Psychology, v. 14, p.219-223, 1986.

MEINCHENBAUM, D. A clinical handbook/practical therapist manual for assessing and treating adults with pos-traumatic stress disorder (PTSD). Waterloo: Institute Press, 1994. 
MONTEIRO, L.; ABREU, V. I.; PHEBO, L. B. Abuso sexual: mitos e realidade. Petrópolis: Autores \& Agentes \& Associados, 1997.

PIRES, J. M. A. Violência na infância: aspectos clínicos. In: AMENCAR (org.). Violência doméstica. Brasília: Unicef, 1999. p.61-70.

PERONE, M. Laboratory lore and research practices in the experimental analysis of human behavior: use and abuse of subjects' verbal reports. The Behavior Analyst, n. I I, p.7I-75, 1988.

SÃO PAULO (Estado). Secretaria da Criança, Família e Bem Estar Social. Estatuto da criança e do adolescente. São Paulo: Governo do Estado de São Paulo, 1997.

SAFFIOTI, H. I. B. Quem mandou nascer mulher? estudos sobre crianças e adolescentes pobres no Brasil. Rio de Janeiro: Rosa dos Tempos, 1996. p. 139-21 I. No fio da navalha.

VOGELTANZ, N. D.; DRABMAN, R. S. A Procedure for evaluating young children suspected of being sexually abused. Behavior Therapy, n. 26, p.579-597, 1995.

WILLIAMS, L. C. de A. Abuso sexual infantil. In: ENCONTRO BRASILEIRO DE PSICOTERAPIA E MEDICINA COMPORTAMENTAL, I0. Resumo de Comunicações Científicas. Campinas, 200।. p. 197.

Violência doméstica: há o que fazer? In: GUILHARDI, H. J. et al. (orgs). Sobre comportamento e cognição: expondo a variabilidade. Santo André: ESETec Editores Associados, 200 la. p. I- 12.

Recebido em: agosto 2002

Aprovado para publicação em: outubro 2002 